\title{
Synthesis of Polylactic Acid (PLA) by Polycondensation Method
}

\author{
T. HoRVÁth ${ }^{1}$, T. J. SZABó2 ${ }^{2}$ K. MAROSSY3 \\ ${ }^{1}$ Institute of Ceramics and Polymer Engineering, Miskolc University, horvath.tibor70@upcmail.hu \\ ${ }^{2}$ Institute of Ceramics and Polymer Engineering, Miskolc University, polsztam@uni-miskolc.hu \\ ${ }^{3}$ Institute of Ceramics and Polymer Engineering, Miskolc University, polkal01@uni-miskolc.hu
}

Abstract. The Polylactic acid (PLA) is compostable and natural renewable sourced plastic type. Its mechanical properties quite similar to the PET, therefore the PLA is a good alternative for strongly ruled food industrial application. The PLA only has one critical attribute - the relatively low glass transition temperature. According to the relevant literature the glass transition of PLA is in the range of $40-70^{\circ} \mathrm{C}$. In light of this fact, this material can be used only in that segments of food industrial field where the packaging process temperature are under of the lower limit of Tg range. The actual Tg of a material is highly depends on the molar mass and material structure, therefore the molar mass and the structure of material should be designed according to the future requirements of application and procedures.

\section{Introduction}

Two basic polymerization process known and being used to produce PLA. The polylactic acid polymer can be synthetized by standard polycondensation and the ring-opening method.

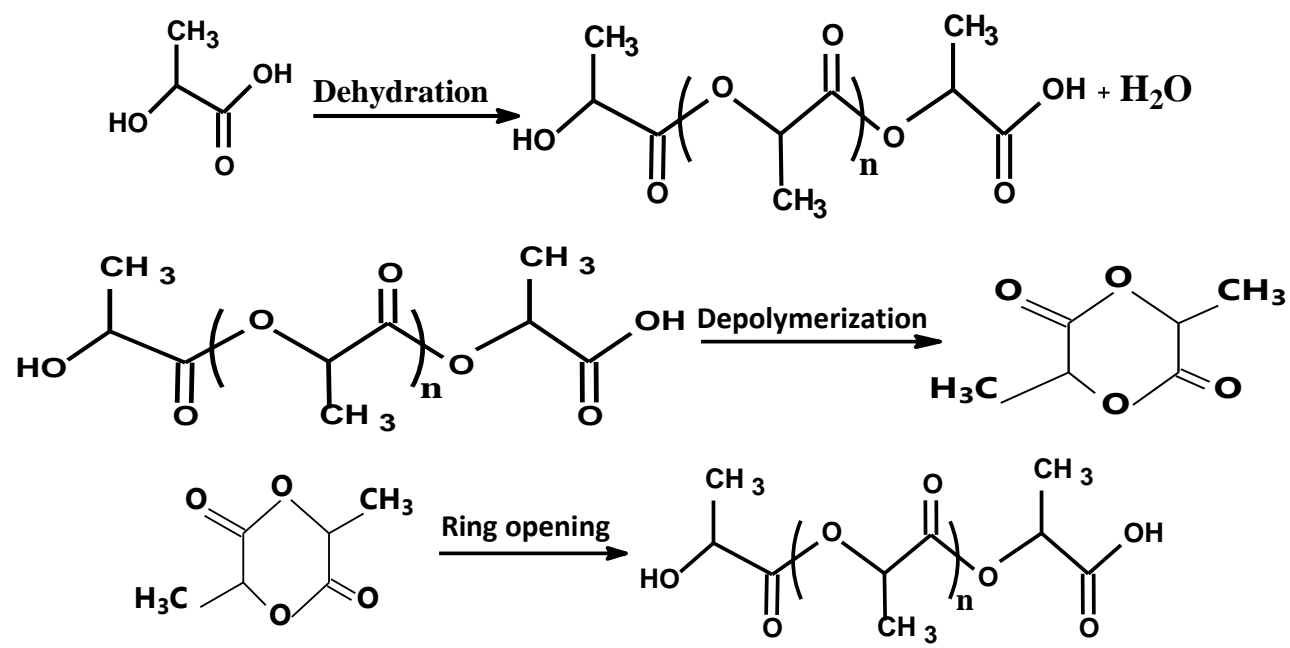

Figure 1. Ring opening polymerization method of PLA [1].

This method is a quite complex procedure as it can be divided for three main phases. In the first step the dehydration of monomer solution and the formation of oligomers need to be executed. This step can be done with short time (1-3 hours) carefully only at moderated temperature to prevent the formation of longer polymer chains. During the second phase the temperature is elevated to 200$220^{\circ} \mathrm{C}$ to recover the lactides (produced at first stage) by distillation. Then the distilled solid dilactides have to be collected and dried. In the third phase $1 \mathrm{w} / \mathrm{w} \%$ catalyst got to be added to the solid lactides 
to initiate the ring opening process and the whole system heated up to $140^{\circ} \mathrm{C}$ for $1-2$ hours to get PLA polymer with high molar mass[2].

There are numerous catalysator known and use in the standard polycondensation and ring-opening methods. The most commonly used catalysators are the stannous chloride $\left(\mathrm{SnCl}_{2}\right)$ [3] and stannous octoate $\left(\mathrm{C}_{16} \mathrm{H}_{30} \mathrm{O}_{4} \mathrm{Sn}\right)$ [4]. At end stage the polymer needs to be removed from the flask by solve the produced polylactic acid in chloroform $\left(\mathrm{CHCl}_{3}\right)$, then precipitate the PLA in methanol $\left(\mathrm{CH}_{3} \mathrm{OH}\right)$.

The standard polycondensation is relatively simpler process as the monomer solution is continuously heated to remove the water form the system, forming getting longer polymer chains by it.

\begin{tabular}{|l|l|l|l|l|l|l|l|}
\hline$\xi$ & 0,5 & 0,8 & 0,9 & 0,95 & 0,99 & 0,998 & 0,999 \\
\hline DP & 2 & 5 & 10 & 20 & 100 & 500 & 1000 \\
\hline
\end{tabular}

Table 1. The connection of DP (degree of polymerization) and conversion rate [5].

$\begin{array}{ll}\text { Carothers equation: } & D P \\ & =\frac{1}{1-\xi}\end{array}$

According to the Carothers equation to get high degree of polymerization (molar mass) is a slow process. Due to this the standard polycondensation is a time-consuming process.

According to the relevant literature polylactic acid (PLA) with $10^{4}-10^{5} \mathrm{~g} \cdot \mathrm{mol}^{-1}$ molar mass can be synthetized by polycondensation. Over the normal thermal initiated polycondensation, microwave initiated method can be applied too as an alternative approach of polymerization. The thermally initiated polycondensation is a quite time-consuming process to reach the above indicated molar mass of PLA. The microwave initiated alternative is a new, faster polycondensation method that can be used successfully as well. In this recent work the standard polycondensation and microwave $\left(\mathrm{M}_{\mathrm{W}}\right)$ initiated method have been used to produce PLA, then compared on basis of time needs.

\section{Experimental}

\subsection{Material and methods}

The raw materials as L and D lactic acids were purchased from Musashino Chemical Laboratory Ltd. The general purity of raw materials was higher than $90 \%$. The other important parameter the stereochemical purity was $>99 \%$. Stannous-Octoate $\left(\mathrm{C}_{16} \mathrm{H}_{30} \mathrm{O}_{4} \mathrm{Sn}\right)$ was chosen to use during the polycondensation that was ensured by University Of Miskolc. For the polycondensation process the following setup have been used: HEIDOLPH Laborota 400 efficient with joined Vacuubrand ME 1C type vacuum pump which was ensured by KISANALITIKA Kft. For the microwave initiated polymerization LG MB-3822G equipment with 700W nominal performance was applied. 


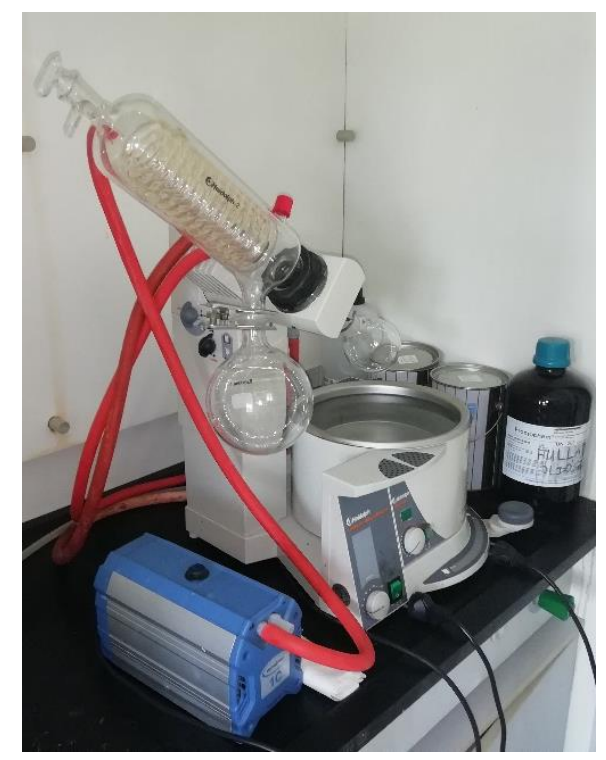

Figure 2. Experimental setup of polycondensation system by HEIDOLPH Laborota 400 efficient with Vacuubrand ME $1 C$ vacuum pump at KISANALITIKA Ltd.

The molar masses of synthetized polymers have been measured by an indirect alternative - capillary viscometry method [6].

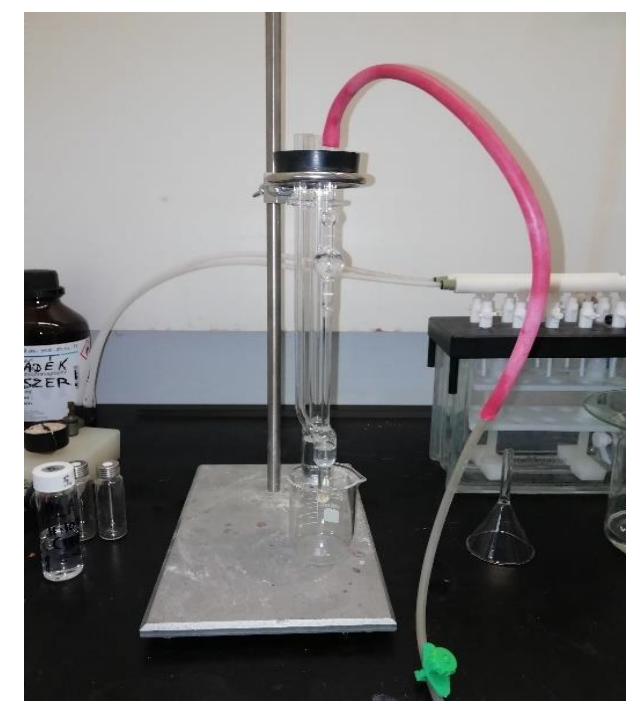

Figure 3. Ubbelohde capillary viscometer [7].

All synthetized polymers have been analyzed by Fourier-transform infrared spectroscopy (FTIR) and Differential scanning calorimetry (DSC). During the FTIR analysis BRUKER Tensor 27, in case of DSC measures DSC131 Evo equipment was used with $\mathrm{dT} / \mathrm{dt}=10^{\circ} \mathrm{C} \mathrm{min}^{-1}$ heating/cooling rate.

\subsection{PLA synthesis by direct polycondensation}

$400 \mathrm{ml}$ lactic acid was added to the one necked reactor flask $(500 \mathrm{ml})$ then it was mounted to manually adjustable HEIDOLPH laborota equipment in line with water-cooling condenser and vacuum pump. In case of preparation of PDLLA the ratio of $L$ and D lactic acids was $50 / 50 \%$. In the first part of 
polymerization the temperature was gradually increased to $120^{\circ} \mathrm{C}$ in 60 minutes, then the reaction was continued for 60 minutes. The reaction mixture was stirred continuously. At the end of prepolymerization $1 \mathrm{wt} \%$ stannous-octoate as catalysator was added to the mixture to support the polymerization process. The pressure of the system was reduced and fixed at $100 \mathrm{mbar}$. The temperature was varied from $160-200^{\circ} \mathrm{C}$, and the reaction time was varied from 48-72 hours. [7] After the polymerisation in case of PLLA the polymer was solved in chloroform then precipitated in methanol. The final solid polymer was dried at $30^{\circ} \mathrm{C}$ at 24 hours.

\subsection{PLA synthesis by microwave initiated polycondensation}

In case of microwave initiated polycondensation the needed energy level ensured by micro wave irradiation except of the standard thermal energy. $160 \mathrm{ml}$ lactic acid was added to a glass pot then it was placed in the center of glass plate. The power output of microwave equipment was set to $700 \mathrm{~W}$ on $2450 \mathrm{Mhz} .1 \mathrm{wt} \%$ catalysator stannous-Octoate was after 20 minutes then the reaction was continued for 14 hours taken samples at reaction time of 2,$5 ; 5 ; 7 ; 9 ; 12$ and 14 hours. [8]

\subsection{DSC analysis of PDLLA and PLLA}

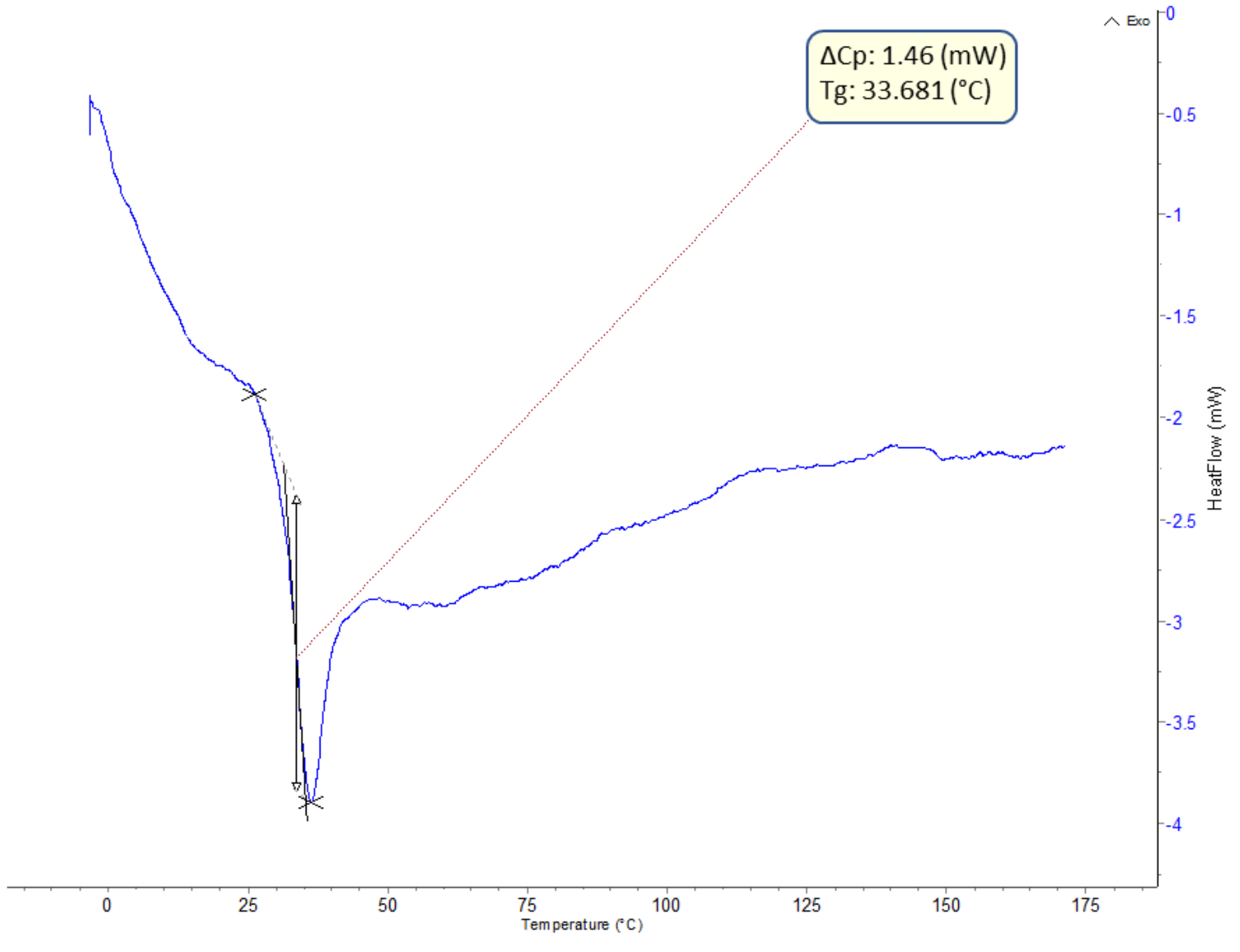

Figure 4. DSC results of PDLLA synthetized by standard polycondensation. 


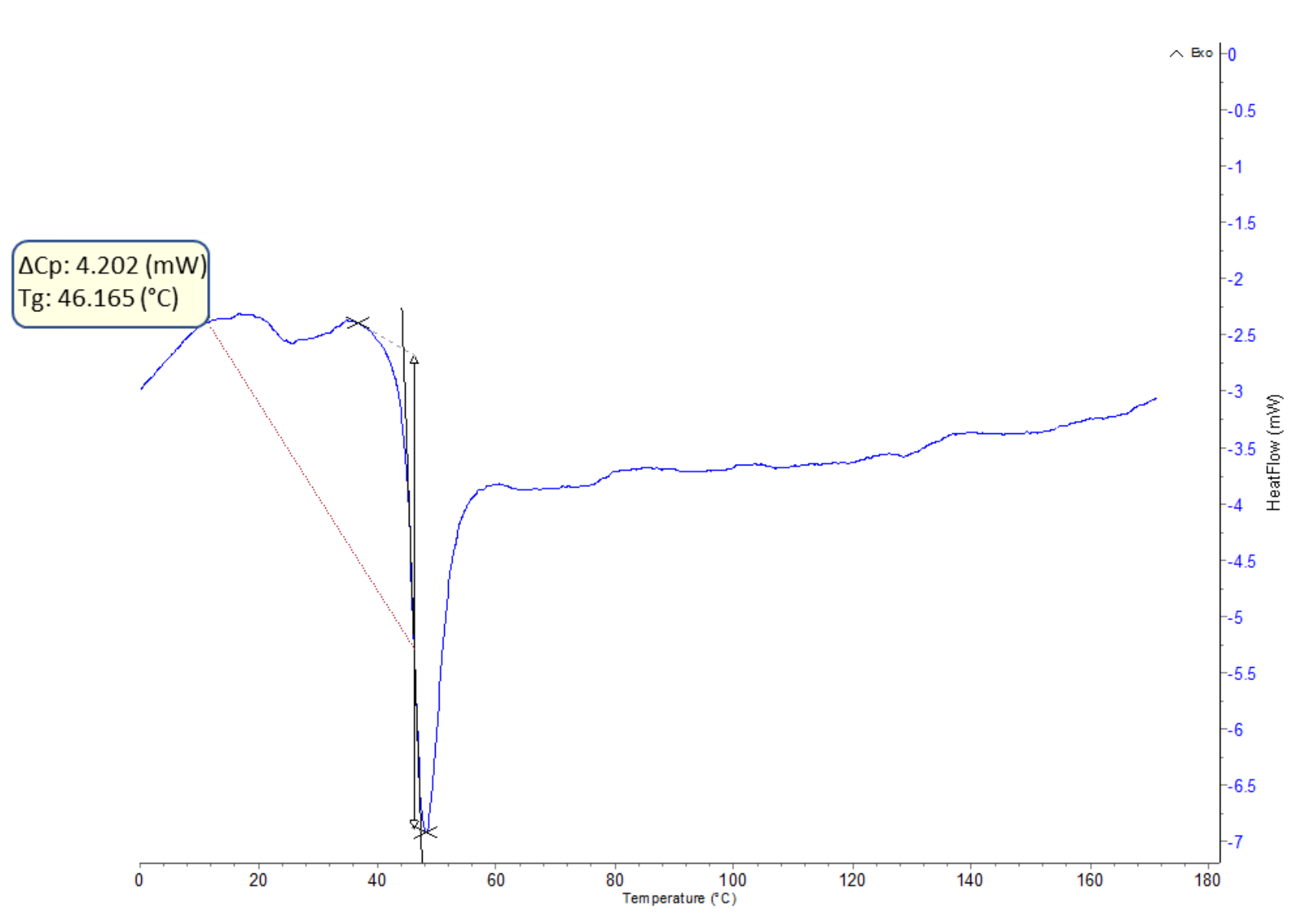

Figure 5. DSC results of PLLA produced by microwave initiated polymerization.

With DSC measurement the glass transition temperatures of all synthetized polymers were defined. In case of samples which were produced by standard polycondensation the following glass transition temperatures were found:

$$
\begin{gathered}
\mathrm{T}_{\mathrm{gPLLA}}=43.7^{\circ} \mathrm{C} \\
\mathrm{T}_{\mathrm{gPDLA}}=41.4^{\circ} \mathrm{C} \\
\mathrm{T}_{\mathrm{gPDLLA}}=33.7^{\circ} \mathrm{C} \text { (fig. } 3 \text { ) }
\end{gathered}
$$

For the PLLA sample that was produced by microwave initiated polymerisation the $\mathrm{Tg}$ was found at $46,16^{\circ} \mathrm{C}$. (Fig 4.) In case of glass transition temperature of PDLLA need to mark that fact the proportion of $\mathrm{L}$ and $\mathrm{D}$ isomers is quite important because the presence and proportion of both stereoisomers in the mixture causing the drop of Tg through plasticizer effect. [9]

Literally both materials (PLLA and PDLLA) are building polymer crystals within proper circumstances. The ratio of crystal parts highly depends on many parameters like; the purity of raw material, the ratio of $\mathrm{L}$ and $\mathrm{D}$ isomers, the speed of heating and cooling processes and the ratio of pre-treatment and preforming of materials. In case of DSC analyzation of two samples as PDLLA which was synthetized by standard polycondensation (Fig 3.) and PLLA that was synthetized by microwave initiated 
polycondensation (Fig 4.), the crystallization and the de-crystallization phases are missing. This anomaly is going to be investigated in separated study.

\subsection{Determination of molar mass of PDLLA and PLLA samples.}

To determinate the molar masses of samples an alternative, indirect method was chosen. During this measurement polymer solutions were prepared with different $0,5 \%, 0,5 \%, 1 \%$ and $2 \%$ concentrations. The solvent was chloroform with $99 \%$ purity. A Ubbelohde capillary viscometer and a stopwatch were used to define the flow times at $25^{\circ} \mathrm{C}$ room temperature. Based on the data the relative viscosity ( $\left.\eta_{\text {rel }}\right)$, the specific viscosity $\left(\eta_{\mathrm{sp}}\right)$ and the reduced specific viscosity $\left(\eta_{\text {red }}\right)$ could be calculated [10].

\begin{tabular}{|c|c|c|c|c|c|}
\hline \multirow{2}{*}{ Type of solution } & \multirow{2}{*}{$\begin{array}{c}\text { Concentration } \\
\%\end{array}$} & \multirow{2}{*}{$\begin{array}{c}\mathrm{C}_{\mathrm{p}} \\
\mathrm{g} \cdot \mathrm{mol}^{-1}\end{array}$} & \multicolumn{3}{|c|}{ Viscosities } \\
\hline & & & $\eta_{\text {rel }}$ & $\eta_{\text {spec }}$ & $\eta_{\text {red }}$ \\
\hline \multirow{5}{*}{ PDLLA } & 2 & 0,02 & 1,15 & 0,15 & 7,63 \\
\hline & 1 & 0,01 & 1,08 & 0,08 & 7,57 \\
\hline & 0,5 & 0,005 & 1,04 & 0,04 & 7,53 \\
\hline & 0,2 & 0,002 & 1,01 & 0,01 & 7,48 \\
\hline & $C \rightarrow 0$ & $C_{p} \rightarrow 0$ & - & - & 7,48 \\
\hline
\end{tabular}

Table 2. Viscosities of PDLLA material that produced by standard polycondensation.

With using the data of reduced specific viscosities, the intrinsic viscosity could be graphically determined [11].

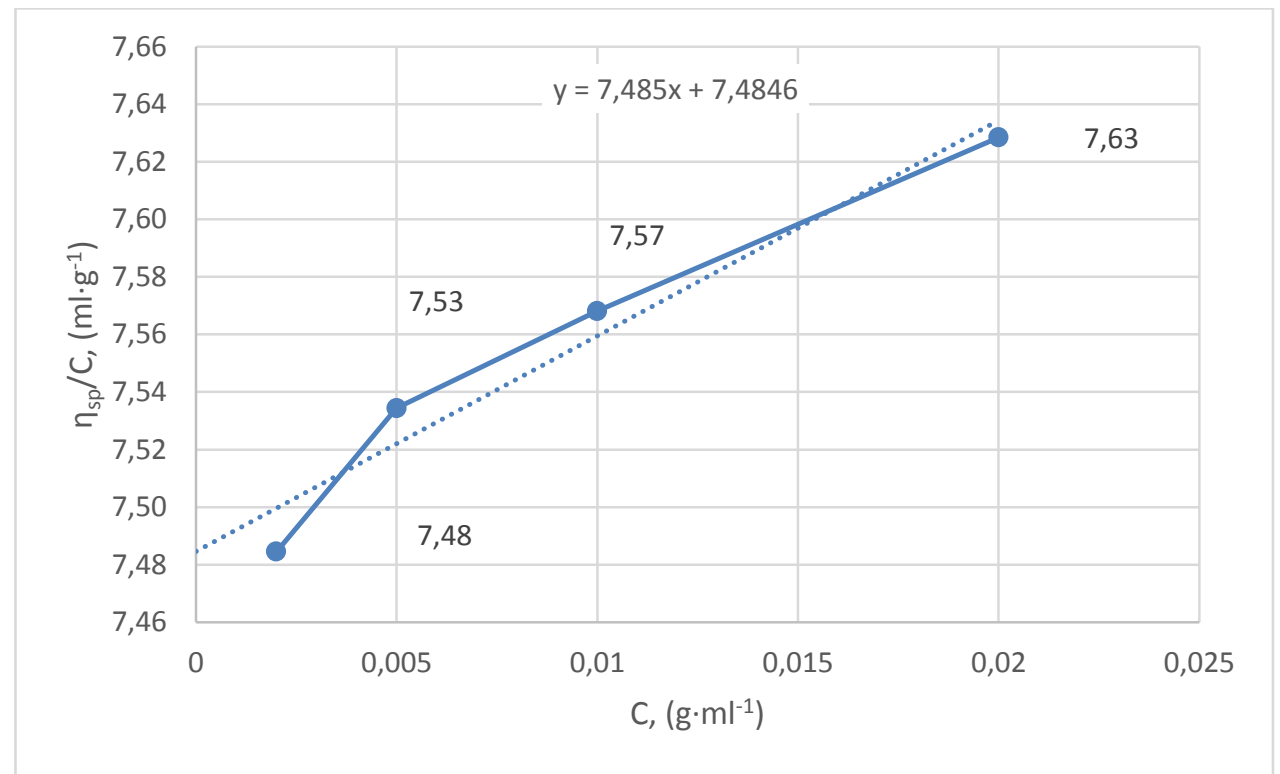

Figure 6. Graphical determination of intrinsic viscosity of PDLLA sample.

By the resulted intrinsic viscosity the molar mass of polymer was defined based on the Mark-Houwink relations [12].

$$
[\eta]=K M^{a}
$$


International Journal of Engineering and Management Sciences (IJEMS) Vol. 5. (2020). No. 2

DOI: 10.21791/IJEMS.2020.2.32.

$$
M=\sqrt[a]{\frac{[\eta]}{K}}
$$

The material specific " $K$ " and " $a$ " constants were taken from relevant literature [13].

$$
\mathrm{K}=0,0066 \quad a=0,67
$$

\begin{tabular}{|c|c|}
\hline Type of polymer & Average molar mass Mv \\
\hline PLLA & $6,97 \times 10^{4} \mathrm{~g} \cdot \mathrm{mol}^{-1}$ \\
\hline PDLA & $1,88 \times 10^{4} \mathrm{~g} \cdot \mathrm{mol}^{-1}$ \\
\hline PLLA $A_{\text {microwave initiated }}$ & $6,84 \times 10^{4} \mathrm{~g} \cdot \mathrm{mol}^{-1}$ \\
\hline PDLLA & $3,6 \times 10^{4} \mathrm{~g} \cdot \mathrm{mol}^{-1}$ \\
\hline
\end{tabular}

Table 3. Calculated molar mass of polymer samples.

\section{Results}

PLA alternatives (as PLLA, PDLA, PDLLA) were synthetized by polycondensation method. In case of PLLA the reaction time was 72 hours to achieve $6,97 \times 10^{4} \mathrm{~g} \cdot \mathrm{mol}^{-1}$ molar mass. For the PDLLA the time of polymerization was 100 hours but due to the heterogenous mixture of $\mathrm{L}$ and D lactices its molar mass $\left(3,6 \times 10^{4} \mathrm{~g} \cdot \mathrm{mol}^{-1}\right)$ couldn't reach the level of PLLA. Regarding the $1,88 \times 10^{4} \mathrm{~g} \cdot \mathrm{mol}^{-1}$ molar mass of homogenous PDLA is caused by the relatively short 48 hours reaction time.

In case of two material samples (PLLA produced by microwave initiated polycondensation, and PDLLA produced by standard polycondensation) the phase of crystallization and de-crystallization haven't been observed.

\section{Conclusion}

Both methods as standard polycondensation and microwave initiated polycondensation can be used to produce PLA. The microwave initiated mod is much more time efficient compared to the standard process. To reach almost the same molar mass of PLLA only 14 hours was enough as total reaction time but the power output of microwave equipment needed to be adjusted carefully because in case of too high power performance the in-production polymer could be easily damaged.

\section{Acknowledgments}

The described work was carried out as part of a project supported by the National Research, Development and Innovation Office - NKFIH, K123456.

\section{References}

[1] Bodnár I - Potenciálisan Biodegradábilis, Politejsav bázisú polimerek szintézise és vizsgálata. Debreceni Egyetem, Alkalmazott Kémiai Tanszék 2002. 
[2] Milena S. Lopes*, André L. Jardini and Rubens M. Filho - Synthesis and Characterizations of Poly (Lactic Acid) by Ring-Opening Polymerization for Biomedical Applications - Chemical Engineering Transactions 2014, Vol. 38.

[3] M. Kaavessina, A. Chafidz, S. Distantina and S. M. Al-Zahrani - Characterization of Poly (lactic acid) Synthesized Via Direct Polycondensation With Different Treatments Of $\mathrm{SnCl}_{2}$ As a Catalyst ARPN Journal of Engineering and Applied Sciences 2016, Vol 11, NO. 16.

[4] P. Laonuad, N. Chaiyut, B. Ksapabutr - Poly(lactic acid) preparation by polycondensation method Optoelectronics And Advanced Materials - Rapid Communications 2010, Vol 4., 1200-1202.

[5] T. Czvikovszky, P. Nagy, J. Gaál - A polimertechnika alapjai - Budapesti Múszaki és Gazdaságtudományi Egyetem (BME) 2007.

[6] J. T. Oberlerchner, T. Rosenau and A. Potthast - Overview of Methods for the Direct Molar Mass Determination of Cellulose - Molecules 2015, Vol. 20, 10313-10341.

[7] P. Laonuad, N. Chaiyut, B. Ksapabutr - Poly(lactic acid) preparation by polycondensation method Optoelectronics And Advanced Materials - Rapid Communications 2010, Vol 4., 1200-1202.

[8] P. Singla, R. Mehta, D. Berek, S. N. Upadhyay - Microwave Assisted Synthesis of Poly(lactic acid) and its Characterization using Size Exclusion Chromatography - Journal of Macromolecular Science, Part A: Pure and Applied Chemistry 2012, Vol. 49, 963-970.

[9] V. Arias, A. Höglund, K. Odelius, A.-C. Albertsson - Polylactides with “Green" Plasticizers: Influence of Isomer Composition - Journal of Applied Polymer Science 2013, Vol. 130, 2962-2970.

[10] https://polymerdatabase.com/polymer\%20physics/Solution_Viscosity.html downloaded at: 28.10 .2019

[11] Szakács H, Dr. Varga Cs, Nagy R - Polimerek méréstechnikája laborgyakorlatok - Pannon Egyetem 2012.

[12] M. R. Kasaai, J. Arul, G. Charlet - Intrinsic Viscosity-Molecular Weight Relationship for Chitosan Journal of Polymer Science Part B Polymer Physics 2000, Vol. 38, 2591 - 2598.

[13] J. E. Mark - Polymer Data Handbook. - Oxford University Press 1999, 629. 